\title{
Using a class wiki to facilitate community and linguistic inclusivity
}

\author{
Christina Bjorndahl*
}

\begin{abstract}
I describe the implementation of a class wiki in an introductory linguistics class. There were two pedagogical goals: (1) facilitate asynchronous student engagement and collaborative learning; (2) provide opportunities for students to engage with various linguistic issues having to do with justice, equity, diversity, and inclusion. Assessment for the wiki was done using a version of specifications grading (Nilson 2015), so that students could choose their level of engagement with the wiki. A full description of the wiki is available at https:// cbjorndahl.github.io/CMUNoLWiki/, which includes detailed descriptions, learning objectives, and prompts given to students for each wiki category. The present paper focusses primarily on the pedagogical motivations, design of the pedagogical intervention, and a reflection of its effectiveness.
\end{abstract}

Keywords. pedagogy; collaborative learning; wiki; JEDI

\section{Introduction.}

1.1. Pedagogical CONTEXT. I teach an introductory linguistics course (80-180) that is offered every semester at CMU, with a cap of 120 students. The linguistics major at CMU is small (approximately 5-9 students), so many students take the course to fulfill their general education requirement. Although it is a first year course, approximately half of the students are in either their third or fourth year, and about $75 \%$ of the students are STEM majors. The course meets three times a week, twice for lectures, and once for a TA-led recitation. In Fall 2020 , lectures were delivered remotely; students attended recitations either remotely or in person, and no "hybrid" sections were offered.

1.2. Instructional goals. Perhaps the best part about introducing students to linguistics is the sheer variety of phenomena that can be brought to bear on class material, and the rapidity with which students can engage in such explorations themselves. The wiki was thus conceived of as a way to facilitate asynchronous student engagement by providing students with an incentivized opportunity to pursue their questions on their own, and share their findings with the class. Additionally, the wiki was structured so that students would participate in collaborative learning, by expanding upon their peers' contributions.

The primary goal of the wiki, however, was to increase the breadth of topics related to justice, equity, diversity, and inclusion (JEDI). As linguists are fond of saying, language is everywhere, and thus so too are the ways in which language and linguistics intersects with JEDI issues. All but one of the wiki categories, listed in (2), were designed so that students would either be engaging with linguistic diversity, or explicitly tackling JEDI issues directly. This feature of the wiki is of particular importance since, given the demographics of the class, most

\footnotetext{
* The development of the wiki was financially supported by the Signature Course initiative and the Department of Philosophy at Carnegie Mellon University. These funds supported a graduate student, Will Nalls, to implement the wiki using PmWiki, a free and open-source platform vetted by CMU for being FERPA compliant. Importantly, a back-end was developed so that grading the wiki was a feasible task for the TAs; the wiki (including the backend) will be available for download as of Summer 2021. Author: Christina Bjorndahl, Carnegie Mellon University (cbjorn@andrew.cmu.edu).
} 
of the students may not have the opportunity to engage with JEDI issues explicitly outside of the class.

2. Why a wiki?. There is an abundance of literature suggesting that wikis can improve student learning (Forte \& Bruckman 2007; Sharp \& Whaley 2018), specifically insofar as they can be used to enhance collaboration in educational settings (Larusson \& Alterman 2009). The inherently collaborative nature of wikis makes them particularly suitable for activities such as group projects (Abdekhodaee et al. 2017) or co-produced writing assignments (Sharp \& Whaley 2018), but they can also be used in activities where the collaboration is less intensive, as in the production of a knowledge base (Cole 2009; Larusson \& Alterman 2009), which is the approach used here.

Although wikis can, in principle, facilitate collaboration, they are not always successful in this respect (Cole 2009; Judd et al. 2010). Moreover, while wikis allow students to edit each other's work, many students feel uncomfortable doing so (Green \& Maxwell 2010). To that end, the wiki described here did not ask students to edit each other's work, and did not students to co-produce writing. Rather, the collaborative focus was that the wiki allowed the class to engage in the co-production of a knowledge bank that reflected student interests within the established wiki categories.

As discussed by Cole (2009), the focus of pedagogical theories have shifted dramatically over the past several decades from teaching to learning. That is, current pedagogical models are learner-centered, with a main tenet being that students learn best when they actively construct knowledge for themselves, using the scaffolding and tools provided by the teacher. The use of wikis as an educational tool aligns well with a particular subtype of constructivist theories of learning which emphasise the social aspect of learning and the co-production of knowledge (c.f Laal \& Ghodsi (2012)). As per Lin \& Hsieh (2001), cooperative theories of learning maintain as core tenets (among others) that "knowledge is created as it is shared, and the more it is shared, the more is learned" and that "learners have prior knowledge they can contribute to the discussion".

To my knowledge, there is no literature that specifically discusses using wikis to tackle JEDI issues in educational settings, but when considered in light of the pedagogical goal to expose students to a wide variety of language topics that interface with JEDI issues, the use of a student-constructed knowledge bank seems particularly appropriate. For example, while discussing descriptivism vs. prescriptivism, I customarily point out that prescriptivist statements are often code for linguistic discrimination, but there are only so many examples I can cover in class. By outsourcing this aspect of content generation to the students, they can become aware of a much broader range of cases.

Another potential benefit of wikis as a way to incorporate JEDI issues relates to providing a means for students from marginalized communities to be compensated for the labour of explaining what it means to experience linguistic discrimination. That is, students who have personal experience with stigmatized dialects or who belong to a community whose perspectives have traditionally been excluded from academia are able (if they wish), to contribute their first-person knowledge to the wiki and receive course credit for doing so. Whether students do in fact take advantage of this remains a question for future study.

3. Description of the pedagogical initiative. Throughout the semester, students contributed to one of several categories, listed in (1), in the form of both articles and expansions. Four 
categories were deemed "essential", which were crucial for defining the levels of engagement, explained below.

(1) Wiki categories

a. Typology of phonetic contrasts

b. Indigenous languages of the Americas (essential)

c. Phonological phenomena in spoken languages

d. Language of the Nacirema (essential)

e. Morphosyntactic diversity (essential)

f. Linguistic discrimination in the wild (essential)

g. Endangered languages

h. Sign languages

i. Varia

The prompt for what counted as an article depended on the category, but was typically a brief (2-3 paragraph) exposition on a particular topic/issue. Students were also required to submit a number of article expansions, writing an additional paragraph building on the work of one of their peers. The purpose of the expansions was so that there was a collaborative component to the wiki, so that students would learn from their peers.

All contributions were worth a specific number of WikiPoints, and assessed as either complete or incomplete, with opportunities to resubmit inadequate contributions. Students had to amass a set number of WikiPoints for three levels of engagement, earning either 15/15 (full engagement), 12/15 (partial engagement), or 10/15 (minimal engagement) for the wiki, which was worth $15 \%$ of their grade. This setup was motivated by specifications-based grading models (Nilson 2015).

\begin{tabular}{lll} 
Contribution & WikiPoints & Description \\
\hline Article & $15 \mathrm{WP}$ & $\begin{array}{l}\text { An article should summarise or explain a topic, in your own words and } \\
\text { using correct terminology. Articles must be submitted before the deadline } \\
\text { to be counted. }\end{array}$ \\
Expansion & $10 \mathrm{WP}$ & $\begin{array}{l}\text { An expansion is a substantial elaboration on another student's article, } \\
\text { either by providing a different kind of explanation, a new example (with } \\
\text { an explanation), or a different perspective. For categories with article } \\
\text { deadlines during the semester, elaborations can be submitted up to one } \\
\text { week past the article deadline, but no later than the last day of class. }\end{array}$ \\
& & $\begin{array}{l}\text { A tidbit is a brief comment on an article or expansion (e.g., posting a rel- } \\
\text { evant link with little to no explanation), or a contribution to a discussion. } \\
\text { Tidbit }\end{array}$ \\
& & $\begin{array}{l}\text { There are no deadlines during the semester for this type of contribution. } \\
\text { These are not graded for content, but they should still be substantive (i.e., } \\
\text { writing "Cool!" on a post won't get any points). }\end{array}$
\end{tabular}

Table 1. Types of wiki contributions

As seen in Table 1, different kinds of contributions were worth a set number of WikiPoints. Students could also contribute a limited number of tidbits, which were not graded and instead were counted automatically. While most students did not abuse this feature (that is, by 
commenting with low-quality comments which could rack up points), some students did, and these were reduced to only worth 1 point in Spring $2021 .^{1}$

As shown in Table 2, the levels of engagement were defined not only in terms of total number of points, but also by how the points were accumulated. For example, students had to contribute articles to three of the four essential categories in order to achieve full engagement, but only had to contribute to two of the four essential categories for partial engagement, one for minimal engagement, etc.

\begin{tabular}{llll} 
& Full & Partial & Minimal \\
\hline Articles & 3 essential $+1=60 \mathrm{WP}$ & 2 essential $+1=45 \mathrm{WP}$ & 1 essential $+1=30 \mathrm{WP}$ \\
Expansions & $3=30 \mathrm{WP}$ & $2=20 \mathrm{WP}$ & $1=10 \mathrm{WP}$ \\
Additional content & $30 \mathrm{WP}$ & $20 \mathrm{WP}$ & $10 \mathrm{WP}$ \\
Total WikiPoints & $120 \mathrm{WP}$ & $85 \mathrm{WP}$ & $50 \mathrm{WP}$ \\
\hline
\end{tabular}

Table 2. Level of engagement

Articles and expansions were assessed on a complete/incomplete basis, with no partial points. There were five criteria given (2), and if a contribution failed in one or more of the criteria, the post was graded as incomplete, with feedback, and students had one week to fix the post.

Wiki criteria
a. Is it correct?
b. Is it complete?
c. Is it relevant?
d. Is it yours?
e. Is it appropriate?

These criteria are more fully elaborated in Section 2.2 of https://cbjorndahl.github.io/ CMUNoLWiki/.

4. Student impressions and effectiveness of the wiki. Given the pedagogical goals outlined in Section 1, there are three dimensions on which to evaluate the effectiveness of the wiki: asynchronous student engagement, the co-production of a student-run knowledge bank, and student learning with respect to JEDI issues as they interface with language and linguistics. Further, an important consideration is student perceptions of the wiki, which is the most common assessment in the literature (Chu et al. 2017; Sharp \& Whaley 2018).

With respect to asynchronous student engagement, most students opted to participate at the full level of engagement, though of course this is likely because grades were associated with the various levels. Given this level of engagement, with nearly 100 students enrolled in

\footnotetext{
${ }^{1}$ In the Fall 2020 implementation, two "Explain it Like I'm 5 (ELI5)" categories (inspired by Reddit) were included, both to incentivize students to ask non-anonymous questions about course material, and to provide an opportunity for students to practice explaining course concepts in an accessible way. Unfortunately, these categories did not appear to accomplish these goals, as many students simply posted questions in order to accumulate points; as a result, these categories were eliminated in the Spring 2021 implementation. A description can be found on the detailed description page of the wiki.
} 
the course and the wide range of contributions, it is clear that the wiki functioned as a studentrun knowledge bank. Some students did share their personal experiences with code switching, stigmatized languages and dialects, and other ways in which their linguistic histories reflect the broad JEDI issues touched upon within the class, while others reported learning a lot from their peers' contributions.

In order to asses more directly how student attitudes changed with respect to JEDI, I administered a language attitudes survey at the beginning and end of the semester (included in the supplementary materials). A full analysis of these pre- and post- results is beyond the scope of this paper, but in general, student perceptions on issues having to do with JEDI did seem to change in a positive direction between the beginning and end of the course. However, it must be kept in mind that it is not clear how much can be attributed to the wiki, as there were numerous pedagogical interventions having to do with JEDI, including lectures, special discussion sections and readings. Nonetheless, there were a couple of responses that were particularly encouraging. For example, one of the questions asked students how much they agreed with the statement, "Reviving dead languages is not a good use of time" (using a standard 5point Likert scale), a topic that was addressed primarily through the wiki category Indigenous Languages of the Americas. Student attitudes towards this topic shifted markedly from the beginning to the end of the semester. Validating the role of the wiki in being the cause of shifts such as this, we can look to the following example of a student's answer to an open-ended question that asked how they think their perspective on JEDI issues has changed:

The most interesting subject in this course for me was the idea of the asymmetrical views on language death held by indigenous peoples and non-indigenous people. The article we read [Leonard (2011)] partway through the course was particularly thought-provoking, and one of the wiki articles I wrote dealt with an American Indian language that was in the process of revitalization. I fell pretty deep down a rabbit hole when researching for that article and ended up on a lot of websites and watching a lot of YouTube videos from people who were trying to revitalize the language. While reading articles was informative, I thought it was really cool to see the specific strategies they were using to bring the language back into prominence in their community, which made the process a lot more real and understandable to me.

In general, students reported enjoying the wiki, often commenting, as above, that they found themselves deeply interested in doing the reading for various topics. The most prevalent criticism was that they did not feel as though the wiki was adequately integrated into the rest of the course material. In response, I created additional connections between the wiki and the remaining class material for the Spring 2021 semester.

5. Conclusion. Constructivist and collaborative models of learning strongly suggest that the use of wikis in the classroom should be an effective tool to enhance collaboration, but the pedagogical literature is mixed on their actual effectiveness and student perceptions. An important lesson learned from the Fall 2020 semester is that incorporating a wiki into the class must also be incorporated into the remaining course material. My experience is that incorporating a wiki into class can be an effective tool both to incorporate additional breadth, and to include additional activities that touch upon JEDI issues. 


\section{References}

Abdekhodaee, Amir, Anne-Marie Chase \& Bella Ross. 2017. Wikis for group work: Encouraging transparency, benchmarking, and feedback. Australasian Journal of Educational Technology 33(5). 15-31. https://doi.org/10.14742/ajet.2829.

Chu, Samuel Kai Wah, Yin Zhang, Katherine Chen, Chi Keung Chan, Celina Wing Yi Lee, Ellen Zou \& Wilfred Lau. 2017. The effectiveness of wikis for project-based learning indifferent disciplines in higher education. The Internet and Higher Education 33. 49-60. https://doi.org/10.1016/j.iheduc.2017.01.005.

Cole, Melissa. 2009. Using Wiki technology to support student engagement: Lessons from the trenches. Computers \& Education 52. 141-146. https://doi.org/10.1016/j.compedu.2008.06.007.

Forte, Andrea \& Amy Bruckman. 2007. Constructing text: Wiki as a toolkit for (collaborative?) learning. In Alain Désilets \& Robert L. Biddle (Eds.), Proceedings of the 2007 international symposium on wikis, 31-42. New York: Association for Computing Machinery.

Green, Marybeth \& Gerri Maxwell. 2010. Wikify your course: Designing and implementing a wiki for your learning environment. Educause Review 33.

Judd, Terry, Gregory Kennedy \& Simon Cropper. 2010. Using wikis for collaborative learning: Assessing collaboration through contribution. Australasian Journal of Educational Technology 26(3). https://doi.org/10.14742/ajet.1079.

Laal, Marjan \& Seyed Mohammad Ghodsi. 2012. Benefits of collaborative learning. ProcediaSocial and Behavioral Sciences 31. 486-490. https://doi.org/10.1016/j.sbspro.2011.12.091.

Larusson, Johann Ari \& Richard Alterman. 2009. Wikis to support the "collaborative" part of collaborative learning. Computer-Supported Collaborative Learning 4. 371-402. https://doi.org/10.1007/s11412-009-9076-6.

Leonard, Wesley Y. 2011. Challenging “extinction” through modern Miami language practices. American Indian Culture and Research Journal 35(2). 135-160.

Lin, Binshan \& Chang-tseh Hsieh. 2001. Web-based teaching and learner control: A research review. Computers \& Education 37. 377-386. https://doi.org/10.1016/S0360-1315(01)00060-4.

Nilson, Linda B. 2015. Specifications grading: Restoring rigor, motivating students, and saving faculty time. Sterling, VA: Stylus Publishing.

Sharp, Laurie A. \& Brigette Whaley. 2018. Wikis as online collaborative learning experiences: "a different kind of brainstorming". Adult Learning 29(3). 83-93. https://doi.org/10.1177/1045159518761095. 